the risk of damaging the product due to local overheating. Electronies have brought a contribution in the evaporation of solutions of heat-sensitive materials such as penicillin by means of radio-frequency dielectric heating, in which the heat is generated directly in the liquid concerned. No temperature gradients are present as is the case when an external source of heat is used and heat transfer has to take place through the wall of the container. Radiofrequency heating is not an economic proposition for heating stable liquids, but may prevent serious losses of activity in heat-sensitive ones. Considerable progress had been made in drying; and spraydrying, flash-drying and drum-drying have been developed with considerable success. The so-called freeze-drying has proved extremely valuable in the final stages of drying penicillin. Much attention has been given to the materials used for the construction of plant and storage vessels. Stainless steel has proved extremely useful, but experience has discovered some important defects in its characteristics which require careful attention; thus when it is welded, seeping may develop through the metal on a line parallel to the weld. Research has shown that if stainless steel is kept for a short time at a temperature of about $650^{\circ} \mathrm{C}$., changes in crystalline structure take place which render the material susceptible to cracking on the application of even slight mechanical stress and to corrosion by liquids which will not attack normal stainless steel. Great care must therefore be taken that it is not subjected to conditions which will take from it the right still to be regarded as stainless steel. bf

\section{Institution of Electrical Engineers}

The May issue of Beflournal of the Institution of Electrical Engineers Mntains a foreword with the heading "Sevent/IVe Years", describing the manner in which theigst founder members of the Institution met in May 1871 , "To consider the expediency of H rm Society of Telegraph Engineers, having for it. objoct the general advancement of electrical and telegraphic science and more particularly for facilitating the exchange of information and ideas among its members". At the outset the Society devoted most of its attention to electrical telegraphy, but in 1879 its scope was enlarged and its title changed to "The Society of Telegraph Engineers and Electricians", in order to provide for the interest aroused by the commercial application of electric lighting. With the rapid development of electrical engineering the title was altered again, to "The Institution of Electrical Engineers", in January 1889, when Sir William Thomson, later Lord Kelvin, delivered the first presidential address to the new body, which was granted a royal charter of incorporation in 1921 . During the seventy-five years of its existence, the Institution has become an important and influential body with nearly 13,500 corporate members and more than 15,000 members of other grades on its register. With the aid of the specialized sections formed in recent years to deal with the fields of installations, measurements, radio and transmission, the Institution caters for this vast membership by pursuing a steady, but vigorous, policy of promoting the general advancement of electrical science and engineering and their applications.

The following have been elected officers of the Institution of Electrical Engineers for 1946-47: President: V. Z. de Ferranti; Vice-Presidents : J. Hacking, T. Graeme N. Haldane, Prof. E. B.
Moullin; Honorary Treasurer: E. Leete; New Members of Council: Dr. T. E. Allibone, D. B. Hoseason, Col. B. H. Leeson, H. Nimmo (members); C. S. Briggs, Dr. F. C. Williams (associate members); . G. Wansbrough (companion). \section{Joints and Sealing nds for Pressure Cablè}

A PAPER by Dpr I. G. Brazier, read in London before the Institat on of Electrical Engineers, discusses the genefer of inciples involved in the design of joints gudseafing ends for pressure-cable installations. Dpsigs standards based on experimeńtal results are g won, and practical methods of construction are described. An account is also given of the gas-control accessories of a pressure cable, including leak location methods. Special attention is given to the problem of voltage surges in relation to joints and sealing ends, and it is shown that the voltage surges specified as representing service conditions are now a critical factor determining the amount of insulation. The relative economics of providing for the voltage surges by additional insulation or alternatively by surge diverters are examined.

\section{A Scottish Statistical Research Bureau}

A Scottish Sphitstical Research Bureau has been set up infolnourgh, following discussions which have tak place between the four Scottish universipips ofd the Faculty of Actuaries. Its object is to plat statistical experience and advice at the disposal of research workers in possession of statistical material. The Bureau functions through a Central Committee, of which the first chairman is Mr. J. G. Kyd, Registrar-General for Scotland and lately president of the Faculty of Actuaries. The secretary is Mr. E. Waugh, Faculty of Actuaries, $23 \mathrm{St}$. Andrew Square, Edinburgh.

Prehistory in South Africa

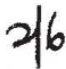

THE first number of a new series of bulletins of the South Africapt Archæological Society, Cape Town, will be of gentotinterest to all prehistorians. These bulletin f will not be confined exclusively to South African Ctudies, but will embrace accounts of research d f cin other areas. The first bulletin, for example, not only describes a preliminary survey of work in South Africa and discusses colour in prehistoric rock paintings, but also includes an account by J. d'A. Waechter of an archæological excavation in the Middle East, and a brief note on the mesolithic cultures of Britain. These bulletins will help to link up more closely South African archæologists, and also act as a convenient medium between them and their colleagues in other countries.

A Blue Moon

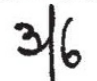

Sky and Telescope for March has an article by J. Hugh Pruett "f the title "Once in a Blue Moon", in which thene is a discussion of the origin of the expresfon ${ }^{\text {t }}$ The chief interest in the article consists, nets 11 me in referring to the theories regarding the orifin of 'a blue moon', as in providing irrefutable evldend from several sources that a blue moon has actually been observed on different occasions. The author of the article states that he saw the phenomenon himself on July 28, 1944. The moon was at the first-quarter phase that day and was thinly veiled by a small patch of high cirrus clouds which were tinted a beautiful orange-red by the sun just below the horizon. It was thought that the lunar blue might be the effect of contrast with the red of the clouds, but this view was shown to be incorrect 
because the moon soon floated out into a clear sky, and was just as blue as ever. Others with Mr. Pruett witnessed the phenomenon, which persisted for 15 minutes but gradually disappeared as the sky darkened. Many others have witnessed a similar occurrence at different times and no explanation is offered for the phenomenon, which is not, of course, astronomical but metporological, and possibly partly psychological.

\section{Bulletin of the Atomic Scientists}

THe Bulletin of the Atomic Scientists, issued by the Atomic Scigntis of Chicago, Inc., is now on sale at a syb̈scr woron of two dollars a year or one dollar for sif iths. Single copies, issued twice a month, a 11 cefts each. From No. 8 (for April 1, 1946), the Bulletin has had sixteen pages or more per issue. The issue for April 1 reprints in condensed form the American State Department Committee's report on the control of atomic energy, together with a draft convention on atomic energy, and an article by Prof. P. M. S. Blackett on atomic energy and the Atomic Energy Committee of the United Nations Organisation. The State Department's report is further discussed in the next issue, which also includes an article on medical and industrial uses of fission-pile products, and the text of the revised McMahon Bill for the control of atomic energy. Articles on "Physics and Politics" by C. E. Merriam, "Science and International Co-operation" by E. U. Condon, "Science and National Policy" by L. A. Du Bridge, and on Hirosh fal a are features of succeeding numbers.

\section{Old Scientific and Medical Books}

Catalogues have recently been issued by $\mathrm{E}$. Weil, of 28 fifchfield Way, London, N.W.11 (No. 8, Alchemf, flemistry and Psychology); and Herbert Rqichney,/34 East 62nd St., New York, 21 (Literafure, History, Art, Law and Science). The former sts some three hundred works, many of which are of importance in the history of science, and some of great rarity. Among them may be mentioned works by Tycho Brahe; Robert Boyle, including one bearing an inscription suggesting former ownership by Robert Hooke ; and a number of original editions of the writings of S. Freud. Other outstanding items are copies of William Withering's "An Account of the Foxglove, and some of its Medical Uses"; a fine copy of an early edition of the "Margarita Philosophica" of Gregorius Reisch ; and an almost perfect copy of Elias Ashmole's "Theatrum Chemicum Britannicum".

Herbert Reichner includes, among the 213 books offered for sale, works of scientific interest on alchemy, chemistry, physics, botany, geology: geography, medicine, and related subjects. Among the more important works listed are a number by or referring to Isaac Newton, with two of his chemical MSS.; a complete set of Dalton's "New System of Chemical Philosophy", all first editions, bearing presentation inseriptions from the author to Sir John Hawkshaw ; and also a set of the original editions of Benjamin Franklin's "Experiments and Observa. tions on Electricity", "Supplemental Experiments" and "New Experiments". Geology is represented by, among other items, a copy of the "De Montium Origine" of Valerio Faenzi, published in Venice in 1561 , an extremely rare work, to which attention was recently directed by the late Prof. F. D. Adams, in his "Birth and Development of the Geological Sciences" ; and by a little-known eighteenth-century systematic treatise on geology, J. S. Schröter's
"Vollständige Einleitung in die Kenntniss und Geschichte der Steine und Versteinerungen".

Both catalogues are, as is usual with these two booksellers, extensively annotated; and that of Herbert Reichner contains a lengthy and valuable list of works of reference used in compiling the catalogue, a number of which are offered for sale.

\section{Colonial Service Appointments}

THe following appointments have been announced by the Colonial Office: D. W. Goodall, to be plant physio/6gist, West African Cocoa Research Institution Gold Coast; G. J. Leggat, to be assistant conservator of forests, Uganda ; Capt. A. E. Dorman, to be veterinary officer, Kenya; R. Miller, to be agricultural superintendent, Nigeria ; Capt. S. Stock, to be geologist, Somaliland; Major P. E. Williams, to be pasture management officer, Department of Science and Agriculture, Jamaica; S. Gillet, senior agricultural officer, and experimentalist, Kenya, to be senior coffee officer, Kenya; L. P. Henderson, senior agricultural officer, Nigeria, to be principal agricultural officer, Nigeria; G. W. Lines, senior agricultural officer, Sierra Leone, to be principal agricultural officer, Sierra Leone; A. E. Moss, agricultural officer, Gold Coast, to be senior agricultural officer, Gold Coast ; B. E. V. Parham, agricultural officer, Fiji, to be senior agricultural officer, Fiji; T. A. Strong, conservator of forests, Ceylon, to be director of forests, Malaya; T. Hirst, deputy director of geological surveys, Gold Coast, to be director of geological surveys, Gold Coast; A. Huddleston, geologist, Gold Coast, to be geologist, Kenya; H. A. Hay Barclay, veterinary officer, Nigeria, to be senior veterinary officer, Nigeria ; J. H. B. Best, senior veterinary officer, Nigeria, to be assistant director of veterinary services, Nigeria; N. Clarke, senior veterinary officer, Nigeria, to be assistant director of veterinary services, Nigeria ; R. Coulthard, senior veterinary officer, Nigeria, to be assistant director of veterinary services, Nigeria; S. G. Wilson, veterinary officer, Nyasaland, to be senior veterinary research officer, Nigeria.

\section{Announcements}

PROF. D. R. HARTREe, professor of theoretical physigs in the University of Manchester, has been appointed Johñ Humphrey Plummer professor of nathematical physics in the University of Cambridge. The chair has been vacant since the death of Sir Ralph Fowler in 1944.

IN recognition of his studies upon chemotherapy in tuberculosis the College of Physicians of Philadelphia has awarded the Alvarenga Prize for this yar to Dr. William H. Feldman, of the Mayo Foundation for Medical Education and Research.

THe Modical Research Council has made arrangements with the Medical School of King's College Hospital, London, for the establishment of a Dental Research Unit there under the direction of Dr. J. D. King, of its scientific staff.

Mr. Frank Twyman has resigned his position as managing director of Adam Hilger, Ltd., which he has hold since 1902, to become technical adviser to the firm and to their associates, E. R. Watts and S6n, Ltd. Mr. Twyman remains chairman of Hilger's. His place as managing director is taken by Mr. G. A. Whipple, who is also managing director of Watts; he is the son of Robert S. Whipple, chairman of the Cambridge Instrument Company. 